\title{
Different Criteria for the Definition of Insulin Resistance and Its Relation with Dyslipidemia in Overweight and Obese Children and Adolescents
}

\author{
Carlos Alberto Nogueira-de-Almeida and Elza Daniel de Mello* \\ Department of Medical, Federal University of São Carlos (UFSCAR), São Carlos, *Department of Pediatric, Federal \\ University of Rio Grande do Sul (UFRGS), Porto Alegre, Brazil
}

\begin{abstract}
Purpose: to compare cut off points corrected for age and gender (COOP) with fixed cut off points (FCOP) for fasting plasma insulin and Homeostatic model assessment-insulin resistance (HOMA-IR) for the diagnosis of IR in obese children and adolescents and their correlation with dyslipidemia.
\end{abstract}

Methods: A multicenter, cross-sectional study including 383 subjects aged 7 to 18 years, evaluating fasting blood glucose, plasma insulin, and lipid profile. Subjects with high insulin levels and/or HOMA-IR were considered as having IR, based on two defining criteria: FCOP or CCOP. The frequency of metabolic abnormalities, the presence of IR, and the presence of dyslipidemia in relation to FCOP or CCOP were analyzed using Fisher and Mann-Whitney exact tests.

Results: Using HOMA-IR, IR was diagnosed in 155 (40.5\%) and 215 (56.1\%) patients and, using fasting insulin, $150(39.2 \%)$ and 221 (57.7\%), respectively applying FCOP and CCOP. The use of CCOP resulted in lower insulin and HOMA-IR values than FCOP. Dyslipidemia was not related to FCOP or CCOP. Blood glucose remained within normal limits in all patients with IR. There was no difference in the frequency of IR identified by plasma insulin or HOMA-IR, both for FCOP and CCOP.

Conclusion: The CCOP of plasma insulin or of HOMA-IR detected more cases of IR as compared to the FCOP, but were not associated with the frequency of dyslipidemia. As blood glucose has almost no fluctuation in this age group, even in the presence of IR, fasting plasma insulin detected the same cases of IR that would be detected by HOMA-IR.

Key Words: Obesity, Insulin, Child, Adolescent, Dyslipidemias

\section{INTRODUCTION}

The prevalence of child and adolescent obesity has increased worldwide [1,2], with the consequent simultaneous increase of several comorbidities [3-7], especially insulin resistance (IR) [8]. IR is consid-

Received : September 27, 2017, Revised : October 24, 2017, Accepted : October 26, 2017

Corresponding author: Carlos Alberto Nogueira-de-Almeida, Department of Medical, Federal University of São Carlos (UFSCAR), Rua Eugênio Ferrante 170, Ribeirão Preto, SP 14027-150, Brazil. Tel: +55-16-99221-7498, Fax: +55-16-38775034, E-mail: dr.nogueira@me.com

Copyright (c) 2018 by The Korean Society of Pediatric Gastroenterology, Hepatology and Nutrition

This is an open-access article distributed under the terms of the Creative Commons Attribution Non-Commercial License (http://creativecommons.org/licenses/by-nc/4.0/) which permits unrestricted non-commercial use, distribution, and reproduction in any medium, provided the original work is properly cited. 
ered the trigger for the onset of the many components of metabolic syndrome (MS) [9-16], which is characterized by a series of comorbidities usually seen in clusters [17] (dyslipidemia, hypertension, diabetes, steatosis, subclinical inflammation, among others), and that are risk factors for cardiovascular disease. Studies have been conducted in order to define the diagnostic criteria and cutoff points to determine IR using Homeostatic model assessment (HOMA)-IR, or fasting plasma insulin, although the first is controversial [18]. The hyperinsulinemic- euglycemic clamp, the gold standard for the diagnosis of IR, is not applicable in clinical practice due to its technical complexity, especially in the pediatric age group [9,19-25]. According to Sinaiko [13], the values of fasting glucose and plasma insulin are the only ones required to calculate HOMA-IR, which intends to demonstrate the correlation between pancreatic capability of insulin production and the capacity of maintaining adequate glucose.

Since in the pediatric age group there is rarely significant variation in blood glucose, some authors suggest that fasting plasma insulin can be used alone for the diagnosis of IR in children [14,22]. There are, however, several limitations to the use of these IR indicators, such as the need to establish a cutoff point related to any associated risk, which is usually obtained through longitudinal and long term studies, and the significant variability of the values of fasting plasma insulin according to age group $[19,20,23,26,27]$.

Moran et al. [27] reported that puberty is a period in which a state of "physiological IR" occurs related to age advancement and independent of changes in body composition. Aradillas-García et al. [28], when evaluating Mexican children and adolescents 6 to 18 years of age, found that both fasting insulin and HOMA-IR, regardless of the presence of obesity, increase gradually until the age of $12-13$ years, and then reach a plateau. A study by Almeida et al. [19], conducted among eutrophic adolescents with mean pubertal development, demonstrated that fasting plasma insulin and HOMA-IR vary significantly according to age, increasing until around 13-15 years, and then decreasing, both for boys and girls. García
Cuartero et al. [20], based on a survey that included 372 subjects aged one month to 18 years, observed a significant variation of fasting plasma insulin and HOMA-IR related to pubertal stage, age and gender. Jeffery et al. [26] have demonstrated that this elevation begins in childhood some years before puberty, and that its onset depends more on age than pubertal staging, questioning the relationship between sexual development and IR.

There is no consensus regarding the reference values of fasting plasma insulin or HOMA-IR for the diagnosis of IR in the pediatric age group and several cutoff points have been reported in the literature [18,28-34]. The most used are $15 \mu \mathrm{U} / \mathrm{mL}$ for fasting plasma insulin [25] and 3.16 for HOMA-IR [21]. Due to the variability of plasma insulin in the pediatric age group, there is a proposal to use cutoff values for HOMA-IR according to gender and pubertal staging [33]. It would be then necessary to add the Tanner criteria in order to identify IR, what limits the use in population studies and adds subjectivity to it.

Based on the study by Almeida [19], and considering the findings of Jeffery et al. [26], that IR depends more on age than on pubertal staging, it is possible to propose specific values of plasma insulin and HOMAIR for each age group and gender. Therefore, this study intended to compare, in a sample of obese children and adolescents, age-adjusted cutoff points, that we called "corrected cut off point" (CCOP) with "fixed cut off point" (FCOP) for fasting plasma insulin and for HOMA-IR for the identification of IR using as outcome the presence of dyslipidemia.

\section{MATERIALS AND METHODS}

A multicenter cross-sectional study was conducted at two outpatient clinics: the Centro de Estudos em Saúde e Nutrologia Infantojuvenil (Center for Studies on Child and Adolescent Nutrition and Health) at the University of Ribeirão Preto (Cesni) and the Ambulatório de Obesidade Infantojuvenil do Serviço de Nutrologia (Nutrology Service: outpatient clinic for Child and Adolescent Obesity) of the Hospital de Clínicas of the Federal University of Rio Grande do 
Sul (AmO). Both are academic services, where data collection follows rigorously standardized methodology. The work was approved by the ethics in research committees of the University of Ribeirão Preto (number 94/2003) and of the Hospital de Clínicas de Porto Alegre (number 07/258). Written Informed Consent was obtained from the subjects.

Inclusion criteria were: all new cases of patients seen between January 2008 and December 2012, aged 7 to 18 years, and with body mass index above the $\mathrm{z}$ score $+\mathrm{l}(\mathrm{n}=489$ eligible). The exclusion criteria were: refusal to sign the consent form $(n=2)$, impossibility to do anthropometry $(n=3)$ or to collect laboratory tests $(n=61)$, other diseases (diabetes mellitus type $1[n=0]$, hypothyroidism $[n=0]$, and inborn errors of metabolism $[n=1]$ ) and incomplete data on medical record $(n=39)$. After meeting the above criteria, 383 subjects were included in the study, 190 of which were seen at Cesni and 193 at Amo.

All were instructed to fast for 12 hours; anthropometric data and blood were collected at the time of the first visit. Weight and height measurements followed the recommendations of the World Health Organization [35]. Two tubes of $4 \mathrm{~mL}$ of blood were collected in a recipient with no additive and sent to the laboratory within two hours for sample processing and biochemical and hormonal analysis. The biological material was separated in a Bio Eng centrifuge model BE 4000 (BIO-ENG, Curitiba, Brazil) running for 5 minutes at 3,500 rpm between one and two and a half hours after harvesting (sufficient time for blood clotting). Biochemical insulin dosage was carried out in one of the aliquots on the day the blood was drawn, by automated chemiluminescence, in a Immulitte DPC Medlab equipment (DPC MEDLAB, Salvador, Brazil). Glucose and lipids were evaluated by the automated enzymatic method with Cobas Mira Plus Roche equipment (Roche Diagnostic Systems, Indianapolis, IN, USA). HOMA-IR was determined applying the equation proposed by Wallace and Matthews [36]: plasma glucose $(\mathrm{mol} / \mathrm{dL}) \times$ plasma insulin $(\mu \mathrm{UI} / \mathrm{mL}) / 22.5$.

Hyperinsulinism, used as a marker of IR, was con- sidered when the plasma insulin concentration was above the cutoff point according to two possibilities:

A) $15 \mu \mathrm{U} / \mathrm{mL}$ FCOP, as usually recommended [25];

B) CCOP for age and gender, adding two standard deviations to the mean values found in a previous study [19] for five age groups. As there is no study with clinical outcomes defining the cut off points adjusted for age, we decided to use a statistical approach, considering as "normal," values of insulin between the average and 2 standards deviation above the average; and "hyperinsulinism" as values higher than this.

- 7 to 8.9 years: $7.92 \mu \mathrm{U} / \mathrm{mL}$ (boys) and 6.70 $\mu \mathrm{U} / \mathrm{mL}$ (girls)

- 9 to 10.9 years: $8.69 \mu \mathrm{U} / \mathrm{mL}$ (boys) and 11.99 $\mu \mathrm{U} / \mathrm{mL}$ (girls)

- 11 to 12.9 years: $12.18 \mu \mathrm{U} / \mathrm{mL}$ (boys) and 13.26 $\mu \mathrm{U} / \mathrm{mL}$ (girls)

- 13 to 14.9 years: $13.74 \mu \mathrm{U} / \mathrm{mL}$ (boys) and 14.85 $\mu \mathrm{U} / \mathrm{mL}$ (girls)

- 15 to 17.9 years: $10.27 \mu \mathrm{U} / \mathrm{mL}$ (boys) and 13.13 $\mu \mathrm{U} / \mathrm{mL}$ (girls)

HOMA-IR was the other diagnostic method for IR, considering the following cutoff points: A) FCOP of 3.16 [21];B) CCOP for age and gender, adding two standard deviations to the mean values found in a previous study [19] for five age groups. As there is no study with clinical outcomes defining the cut off points adjusted for age, we decided to use a statistical approach, considering as "normal," values of HOMAIR between the average and 2 standards deviation above the average; and "High HOMA-IR" as values higher than this.

- 7 to 8.9 years: 1.76 (boys) and 1.39 (girls)

- 9 to 10.9 years: 1.97 (boys) and 2.62 (girls)

- 11 to 12.9 years: 2.65 (boys) and 3.02 (girls)

- 13 to 14.9 years: 3.21 (boys) and 3.46 (girls)

- 15 to 17.9 years: 2.39 (boys) and 2.89 (girls)

The cutoff points used to define dyslipidemia were proposed in Brazil by the "I guidelines of prevention of atherosclerosis in childhood and adolescence" [37]: total cholesterol (TC) $>150 \mathrm{mg} / \mathrm{dL}$; low density lipoprotein cholesterol (LDL-C) $>100 \mathrm{mg} / \mathrm{dL}$; high density lipoprotein cholesterol (HDL-C) $<45 \mathrm{mg} / \mathrm{dL}$; 
triglycerides $(\mathrm{TG})>100 \mathrm{mg} / \mathrm{dL}$.

The variables studied were: 1) gender-related frequency of metabolic abnormalities; 2) presence or absence of IR in relation to plasma insulin or HOMA-IR FCOP or CCOP for age; and 3) the frequency of dyslipidemia in children with IR, also according to FCOP and CCOP.

The computer program Graphpad Prism 5 was used for statistical analysis. Fisher's exact test (twosided) was used to compare frequencies, and MannWhitney test to compare non-parametric data, considering statistical difference when $p<0.05$. The results were presented as mean \pm standard error of the mean (SEM) or percentage.

\section{RESULTS}

Table 1 depicts the demographic and laboratory characteristics of the 383 children evaluated (mean \pm SEM). This sample consisted of 55\% females, with a mean age of $11.3 \pm 0.1$ year and body mass index $\mathrm{z}$ score of +2.4. Among these, 221 (57.7\%) and 217 $(56.7 \%)$ presented IR according to increased (fixed or corrected) values of fasting plasma insulin or HOMA-IR, respectively.
For patients diagnosed with IR according to fasting plasma insulin, the use of CCOP resulted in significantly lower values of fasting plasma insulin and HOMA-IR as compared to those obtained using FCOP, although still quite high in relation to the whole sample. A similar result was found in the patients diagnosed with IR by HOMA-IR as compared to fasting plasma insulin values, but not when compared to HOMA-IR values. Table 1 also shows that the mean values for TC, HDL-C, and TG were abnormal regardless of whether FCOP or CCOP of fasting plasma insulin or of HOMA-IR were considered. Blood glucose remained within normal values in all patients with IR, regardless of the type of cutoff values used for fasting plasma insulin or HOMA-IR.

The frequency (\%) of metabolic abnormalities found in relation to gender is depicted in Table 2 . Using insulin with FCOP, $33.1 \%$ of boys and $44.1 \%$ of girls had IR and using HOMA with FCOP, the prevalence was $37.8 \%$ and $42.7 \%$, respectively. Using insulin with CCOP, $57.6 \%$ of boys and $57.8 \%$ of girls had IR and using HOMA with CCOP, the prevalence was $57.0 \%$ and $55.5 \%$, respectively. There was no difference between boys and girls in the frequency of IR identified by FCOP or CCOP of fasting plasma insulin

Table 1. Demographic and Laboratory Characteristics of a Sample of Obese Children and Adolescents with Insulin Resistance according to Fixed or Variable Cutoff Points of Fasting Plasma Insulin or of HOMA-IR

\begin{tabular}{|c|c|c|c|c|c|c|c|}
\hline \multirow{2}{*}{ Characteristic } & \multirow{2}{*}{ All $(n=383)$} & \multicolumn{3}{|c|}{ Increased plasma insulin } & \multicolumn{3}{|c|}{ Increased HOMA-IR } \\
\hline & & FCOP $(n=150)$ & $\operatorname{CCOP}(n=221)$ & $p$-value & FCOP $(n=155)$ & CCOP $(n=215)$ & $p$-value \\
\hline Gender (male:female) & $1: 2$ & $1: 1.6$ & $1: 1.4$ & NS & $1: 2$ & $1: 2$ & NS \\
\hline Age $(y)$ & $11.3 \pm 0.1$ & $11.9 \pm 0.2$ & $11.0 \pm 0.2$ & NS & $11.7 \pm 0.2$ & $10.9 \pm 0.2$ & NS \\
\hline Z score (weight) & $2.4 \pm 0.0$ & $2.7 \pm 0.1$ & $2.9 \pm 0.1$ & NS & $2.8 \pm 0.1$ & $2.9 \pm 0.1$ & NS \\
\hline Total cholesterol $(\mathrm{mg} / \mathrm{dL})$ & $164.1 \pm 1.6$ & $163.3 \pm 2.5$ & $164.4 \pm 2.1$ & NS & $162.9 \pm 2.5$ & $165.6 \pm 2.1$ & NS \\
\hline LDL-C $(\mathrm{mg} / \mathrm{dL})$ & $97.7 \pm 1.5$ & $96.3 \pm 2.5$ & $97.8 \pm 2.0$ & NS & $96.3 \pm 2.4$ & $99.5 \pm 1.9$ & NS \\
\hline HDL-C (mg/dL) & $46.0 \pm 0.6$ & $44.1 \pm 0.9$ & $44.6 \pm 0.7$ & NS & $43.8 \pm 0.8$ & $45.3 \pm 0.7$ & NS \\
\hline Triglycerides $(\mathrm{mg} / \mathrm{dL})$ & $105.1 \pm 2.8$ & $122.8 \pm 5.3$ & $117.4 \pm 4.1$ & NS & $122.9 \pm 5.3$ & $111.0 \pm 4.2$ & NS \\
\hline Fasting glucose (mg/dL) & $87.5 \pm 0.5$ & $89.3 \pm 0.8$ & $89.3 \pm 0.6$ & NS & $90.3 \pm 0.8$ & $89.5 \pm 0.6$ & NS \\
\hline Plasma insulin $(\mu \mathrm{U} / \mathrm{mL})$ & $16.0 \pm 0.7$ & $27.0 \pm 1.3$ & $22.1 \pm 1.0$ & $0.003^{*}$ & $26.4 \pm 1.3$ & $22.2 \pm 1.0$ & $0.02^{*}$ \\
\hline HOMA-IR & $3.5 \pm 0.2$ & $6.1 \pm 0.4$ & $4.9 \pm 0.4$ & $0.002^{*}$ & $6.0 \pm 0.4$ & $5.0 \pm 0.3$ & NS \\
\hline
\end{tabular}

Values are presented as number only or mean \pm standard error of the mean.

HOMA-IR: Homeostatic model assessment-insulin resistance, FCOP: fixed cut off point (fasting plasma insulin $>15 \mu \mathrm{U} / \mathrm{mL}$, HOMA-IR > 3.16), CCOP: corrected cut off point (according to age and gender), NS: not significant, LDL-C: low density lipoprotein cholesterol, HDL-C: high density lipoprotein cholesterol.

*Exact Fisher's test. 
Table 2. Gender-Related Frequency (\%) of Metabolic Abnormalities in a Sample of Obese Children and Adolescents

\begin{tabular}{lcc}
\hline \multicolumn{1}{c}{ Variable } & $\begin{array}{c}\text { Male } \\
(\%,\end{array}$ & $\left.\begin{array}{c}\text { Female } \\
(\%,\end{array}\right)$ \\
& 6.4 & $\mathrm{n}=21 \mathrm{l})$ \\
\hline Fasting glucose $>100 \mathrm{mg} / \mathrm{dL}$ & 65.7 & 64.9 \\
Total cholesterol >150 mg/dL & 44.8 & 46.4 \\
LDL-C >100 mg/dL & 44.8 & 52.6 \\
HDL-C $<45 \mathrm{mg} / \mathrm{dL}$ & 44.8 & 46.0 \\
Triglycerides >100 mg/dL & & \\
Increased plasma insulin & 33.1 & 44.1 \\
FCOP & 57.6 & 57.8 \\
CCOP & & \\
Increased HOMA-IR & 37.8 & 42.7 \\
FCOP & 57.0 & 55.5 \\
CCOP &
\end{tabular}

LDL-C: low density lipoprotein cholesterol, HDL-C: high density lipoprotein cholesterol; FCOP: fixed cut off point (fasting plasma insulin $>15 \mu \mathrm{U} / \mathrm{mL}$, HOMA-IR >3.16), CCOP: corrected cut off point (according to age and gender), HOMA-IR: Homeostatic model assessment-insulin resistance. Exact Fisher's test $p>0.05$. or of HOMA-IR.

Table 3 depicts the distribution of patients with or without IR, according to the use of FCOP or CCOP. Using fasting plasma insulin or HOMA-IR CCOP, as compared to FCOP, there was concordance in 150 $(68.0 \%)$ and $153(70.0 \%)$ subjects, respectively, and discrepancy in $71(32.1 \%)$ and 62 cases $(28.6 \%)$ for the diagnosis of IR. On the other hand, for the diagnosis of absence of IR, CCOP was consonant with FCOP in $162(73.3 \%)$ and $166(76.5 \%)$ for fasting plasma insulin and HOMA-IR, respectively, and discrepant in none for fasting plasma insulin and in 2 for fasting HOMA-IR.

The frequency (\%) of lipid changes in the sample of patients with IR according to the cutoff criteria for fasting plasma insulin and HOMA-IR is depicted in Table 4. The frequency of dyslipidemia was also high, being above $50 \%$ for all indicators evaluated.

Table 3. Distribution of Children according to the Presence or Absence of Insulin Resistance Using Fixed or Variable Cutoff Points of Fasting Plasma Insulin or of HOMA-IR

\begin{tabular}{|c|c|c|c|c|c|c|c|}
\hline \multicolumn{4}{|c|}{ Increased fasting plasma insulin } & \multicolumn{4}{|c|}{ Increased HOMA-IR } \\
\hline & FCOP & & Total & & FCOP & & Total \\
\hline CCOP & + & - & & СCOP & + & - & \\
\hline+ & 150 & 71 & 221 & + & 153 & 62 & 215 \\
\hline- & 0 & 162 & 162 & - & 2 & 166 & 168 \\
\hline Total & 150 & 233 & 383 & Total & 155 & 228 & 383 \\
\hline
\end{tabular}

HOMA-IR: Homeostatic model assessment-insulin resistance, FCOP: fixed cut off point (fasting plasma insulin $>15 \mu \mathrm{U} / \mathrm{mL}$, HOMA-IR >3.16), CCOP: corrected cut off point (according to age and gender).

Exact Fisher's test $p<0.0001$.

Table 4. Comparison of Dyslipidemia Frequencies in Children with Insulin Resistance Assessed by Fixed or Age-Adjusted Cutoff Points of Insulin or of HOMA-IR

\begin{tabular}{lccccc}
\hline \multirow{2}{*}{ Alteration $(\mathrm{mg} / \mathrm{dL})$} & \multicolumn{2}{c}{ Increased plasma insulin $(\%)$} & & \multicolumn{2}{c}{ Increased HOMA-IR $(\%)$} \\
\cline { 2 - 3 } \cline { 5 - 6 } & FCOP $(\mathrm{n}=150)$ & CCOP $(\mathrm{n}=221)$ & & FCOP $(\mathrm{n}=155)$ & CCOP $(\mathrm{n}=215)$ \\
\hline Total cholesterol $\geq 150$ & 60.7 & 62.9 & 60.0 & 63.3 \\
LDL-C $\geq 100$ & 44.7 & 45.2 & 55.1 & 45.1 \\
HDL-C $\leq 45$ & 54.7 & 52.9 & 56.7 & 53.5 \\
Triglycerides $\geq 100$ & 59.3 & 54.3 & 59.3 & 55.8 \\
Fasting glucose $\geq 100$ & 6.7 & 7.7 & 8.4 & 7.9 \\
\hline
\end{tabular}

HOMA-IR: Homeostatic model assessment-insulin resistance, FCOP: fixed cut off point (fasting plasma insulin $>15 \mu \mathrm{U} / \mathrm{mL}$, HOMA-IR >3.16), CCOP: corrected cut off point (according to age and gender), LDL-C: low density lipoprotein cholesterol, HDL-C: high density lipoprotein cholesterol.

Mann-Whitney test $p>0.05$. 


\section{DISCUSSION}

The objective of this study was to compare, in a sample of 383 children and adolescents with excess weight, the criteria of age and gender CCOP with one of the criteria of FCOP for fasting plasma insulin and for HOMA-IR adopted in the literature, used to identify IR, and its correlation with dyslipidemia. The frequency of IR identified by the use of the fasting plasma insulin and HOMA-IR CCOP was $57.7 \%$ and $56.1 \%$, whereas the FCOP identified $39.2 \%$ and $40.5 \%$ patients with IR, respectively (Tables 1 and 3 ). This frequency is similar to that found in 466 Mexican obese adolescents aged 11 to 13 years, using a HOMA-IR FCOP of 3.4 [38]. In this study, CCOP enabled the identification of more cases of IR than FCOP. Nevertheless, fasting insulin and HOMA-IR values in patients with IR identified by increased fasting plasma insulin were significantly lower when CCOP was used as compared to FCOP (Table 1).

When CCOP of fasting plasma insulin and of HOMA-IR were used, as compared to FCOP, the authors found intense correlation both for the diagnosis of IR as for the absence of IR (Table 3).

In other studies, which used multivariate regression analysis, a positive association was found between the female gender and the presence of IR $[39,40]$. In our sample, however, no significant difference was seen in the frequency of IR in relation to gender, corroborating previous results obtained in eutrophic children and adolescents [19] (Table 2). It is important to note that, in the studies mentioned, lower FCOPs were used than those employed in this study (HOMA-IR greater than or equal to 3.16).

Another objective of our study was to evaluate the frequency of some of the outcomes often found in MS, such as dyslipidemia and abnormal fasting glucose, in the presence of IR, identified by different cutoff criteria for fasting plasma insulin and for HOMA-IR. Many researchers have identified a correlation between markers of IR and the classic components of MS, especially hypertriglyceridemia, low HDL-C, hypertension, and increased waist circumference, both in adults and in children and adoles- cents of different ethnicities [38,41-44]. In this study, the frequency of metabolic alterations such as increased TC, LDL-C and TG, decreased HDL-C, and abnormal fasting glucose in cases of IR, identified according to CCOP of fasting plasma insulin and of HOMA-IR, was similar to those found using FCOP (Table 3). Juárez-López et al. [38] demonstrated that in a sample of Mexican obese children, the most frequent metabolic alteration was low HDL-C (69\%), followed by increased TG (29\%), TC and LDL-C ( $11 \%)$, and glucose (4\%). However, they used values of HOMA-IR greater or equal to 3.4 for the diagnosis of IR and different criteria for the definition of dyslipidemia.

Corroborating with the findings by other authors $[8,22]$, this study found that fasting glucose values were within normal limits regardless of the method or cutoff point used for the diagnosis of IR (Table 1). Since fasting glucose varies little in the pediatric age group, many authors suggest that the use of HOMAIR for the diagnosis of IR would be unnecessary, since the component of the equation that effectively varies is plasma insulin, therefore being sufficient for the diagnosis [14,22]. In fact, in our cases, it was noted that the results of IR and metabolic abnormalities, using fasting plasma insulin or HOMA-IR were similar.

Our study has limitations such as the small number of patients, its cross-sectional design, unavailability of a control group and of other clinical and laboratory outcomes related to IR (hypertension, waist circumference, steatosis, etc.), arbitrariness of the definitions for corrected cutoff points (two standard deviations above the mean), and the lack of comparison with a validated diagnostic method of IR. Ideally, it would be best if this definition came from longitudinal, risk association studies; however, these have not been published to this day. Nonetheless, it should be noted that this study was the first to compare two criteria for the definition of cutoff points of fasting plasma insulin and of HOMA-IR for the diagnosis of IR and the first to describe the frequency of metabolic alterations according to these criteria. 
For the clinician, this study shows the importance of always evaluating values of fasting insulin and HOMA-IR together with the age. Additionally, it is very important to remember that the hyperglycemia is not common, but it is fundamental that some evaluation of insulin resistance is used, because this phenomenon is the first step of a probable type 2 diabetes.

Based on this research, it can be concluded that, among children and adolescents with excess weight: 1) fasting plasma insulin and/or HOMA-IR CCOP enabled more diagnosis of IR as compared to FCOP; 2) the frequencies of metabolic abnormalities in the subjects with IR defined with CCOP were similar to those found using FCOP; the frequency of detection of IR by HOMA-IR was similar to that by fasting plasma insulin, regardless of the cutoff point used; hyperglycemia was not prevalent.

\section{ACKNOWLEDGEMENTS}

The authors thanks to Dr. Ana Valeria B. Castro for her help on endocrinological concepts.

\section{REFERENCES}

1. Ng M, Fleming T, Robinson M, Thomson B, Graetz N, Margono C, et al. Global, regional, and national prevalence of overweight and obesity in children and adults during 1980-2013: a systematic analysis for the Global Burden of Disease Study 2013. Lancet 2014;384:766-81.

2. de Onis M. Preventing childhood overweight and obesity. J Pediatr (Rio J) 2015;91:105-7.

3. Nogueira-de-Almeida CA, Benedeti ACGS, Garcia J, Caixe SH. Correlation between ultrasonographic measures of the abdominal adiposity and indicators of obesity in normal and overweight/obesity children. The FASEB Journal 2016;30:1165.4.

4. Nogueira-de-Almeida CA, Caixe SH, Benedeti ACGS, Garcia J. Echocardiography evaluation as a marker of cardiovascular risk on obese children and adolescents. The FASEB Journal 2016;30:126.1.

5. Nogueira-de-Almeida CA, Garcia J, Caixe SH, Benedeti ACGS. Ultrasonographic assessment of the common carotid intima-media complex in normal weight children and in overweight/obese children. The FASEB Journal 2016;30:1165.3.

6. Nogueira-de-Almeida CA, Pires LAF, dos Santos RG.
Comparação de indicadores de perfis glicêmico e lipídico entre crianças e adolescentes obesos egressos de serviço público ou privado da cidade de Ribeirão Preto (SP). Medicina 2016;49:504-10.

7. Todendi PF, Valim AR, Reuter CP, Mello ED, Gaya AR, Burgos MS. Metabolic risk in schoolchildren is associated with low levels of cardiorespiratory fitness, obesity, and parents' nutritional profile. J Pediatr (Rio J) 2016;92:388-93.

8. Sekokotla MA, Goswami N, Sewani-Rusike CR, Iputo JE, Nkeh-Chungag BN. Prevalence of metabolic syndrome in adolescents living in Mthatha, South Africa. Ther Clin Risk Manag 2017;13:131-7.

9. Harrell JS, Jessup A, Greene N. Changing our future: obesity and the metabolic syndrome in children and adolescents. J Cardiovasc Nurs 2006;21:322-30.

10. Maffeis C, Banzato C, Brambilla P, Cerutti F, Corciulo $\mathrm{N}$, Cuccarolo $\mathrm{G}$, et al. Insulin resistance is a risk factor for high blood pressure regardless of body size and fat distribution in obese children. Nutr Metab Cardiovasc Dis 2010;20:266-73.

11. Must A, Jacques PF, Dallal GE, Bajema CJ, Dietz WH. Long-term morbidity and mortality of overweight adolescents. A follow-up of the Harvard Growth Study of 1922 to 1935. N Engl J Med 1992;327:1350-5.

12. Sanches Pde L, Mello MT, Fonseca FA, Elias N, Piano Ad, Carnier J, et al. Insulin resistance can impair reduction on carotid intima-media thickness in obese adolescents. Arq Bras Cardiol 2012;99:892-8.

13. Sinaiko A. Obesity, insulin resistance and the metabolic syndrome. J Pediatr (Rio J) 2007;83:3-4.

14. Weiss R, Dziura J, Burgert TS, Tamborlane WV, Taksali SE, Yeckel CW, et al. Obesity and the metabolic syndrome in children and adolescents. N Engl J Med 2004;350:2362-74.

15. Zachurzok-Buczyńska A, Klimek K, Firek-Pedras M, Małecka-Tendera E. Are metabolic syndrome and its components in obese children influenced by the overweight status or the insulin resistance? Endokrynol Pol 2011;62:102-8.

16. Zimmet P, Alberti KG, Kaufman F, Tajima N, Silink M, Arslanian S, et al. The metabolic syndrome in children and adolescents-an IDF consensus report. Pediatr Diabetes 2007;8:299-306.

17. Pinho AP, Brunetti IL, Pepato MT, de Almeida CAN. Metabolic syndrome in overweight/obese female adolescents. Rev Paul Pediatr 2012;30:51-6.

18. Levy-Marchal C, Arslanian S, Cutfield W, Sinaiko A, Druet C, Marcovecchio ML, et al. Insulin resistance in children: consensus, perspective, and future directions. J Clin Endocrinol Metab 2010;95:5189-98. 
19. Almeida CA, Pinho AP, Ricco RG, Pepato MT, Brunetti IL. Determination of glycemia and insulinemia and the homeostasis model assessment (HOMA) in schoolchildren and adolescents with normal body mass index. J Pediatr (Rio J) 2008;84:136-40.

20. García Cuartero B, García Lacalle C, Jiménez Lobo C, González Vergaz A, Calvo Rey C, Alcázar Villar MJ, et al. The HOMA and QUICKI indexes, and insulin and C-peptide levels in healthy children. Cut off points to identify metabolic syndrome in healthy children. An Pediatr (Barc) 2007;66:481-90.

21. Keskin M, Kurtoglu S, Kendirci M, Atabek ME, Yazici C. Homeostasis model assessment is more reliable than the fasting glucose/insulin ratio and quantitative insulin sensitivity check index for assessing insulin resistance among obese children and adolescents. Pediatrics 2005;115:e500-3.

22. Mieldazis SF, Azzalis LA, Junqueira VB, Souza FI, Sarni RO, Fonseca FL. Hyperinsulinism assessment in a sample of prepubescent children. J Pediatr (Rio J) 2010;86:245-9.

23. Moran A, Jacobs DR Jr, Steinberger J, Hong CP, Prineas R, Luepker R, et al. Insulin resistance during puberty: results from clamp studies in 357 children. Diabetes 1999;48:2039-44.

24. Pastucha D, Filipčíková R, Horáková D, Radová L, Marinov Z, Malinčíková J, et al. The incidence of metabolic syndrome in obese Czech children: the importance of early detection of insulin resistance using homeostatic indexes HOMA-IR and QUICKI. Physiol Res 2013;62:277-83.

25. Ten S, Maclaren N. Insulin resistance syndrome in children. J Clin Endocrinol Metab 2004;89:2526-39.

26. Jeffery AN, Metcalf BS, Hosking J, Streeter AJ, Voss LD, Wilkin TJ. Age before stage: insulin resistance rises before the onset of puberty: a 9-year longitudinal study (EarlyBird 26). Diabetes Care 2012;35:536-41.

27. Moran A, Jacobs DR Jr, Steinberger J, Steffen LM, Pankow JS, Hong CP, et al. Changes in insulin resistance and cardiovascular risk during adolescence: establishment of differential risk in males and females. Circulation 2008;117:2361-8.

28. Aradillas-García C, Rodríguez-Morán M, Garay-Sevilla ME, Malacara JM, Rascon-Pacheco RA, Guerrero-Romero F. Distribution of the homeostasis model assessment of insulin resistance in Mexican children and adolescents. Eur J Endocrinol 2012;166:301-6.

29. Barja S, Arteaga A, Acosta AM, Hodgson MI. Insulin resistance and other expressions of metabolic syndrome in obese Chilean children. Rev Med Chil 2003;131:259-68.

30. Brasil AR. Crianças e adolescentes com sobrepeso ou obesidade: avaliação da reação inflamatória através da dosagem da proteína c-reativa ultra-sensível e prevalência de síndrome metabólica. Belo Horizonte: UFMG, 2006.

31. da Silva RC, Miranda WL, Chacra AR, Dib SA. Metabolic syndrome and insulin resistance in normal glucose tolerant brazilian adolescents with family history of type 2 diabetes. Diabetes Care 2005;28:716-8.

32. DeFronzo RA. Lilly lecture 1987 . The triumvirate: beta-cell, muscle, liver. A collusion responsible for NIDDM. Diabetes 1988;37:667-87.

33. Kurtoğlu S, Hatipoğlu N, Mazıcıŏglu M, Kendirici M, Keskin M, Kondolot M. Insulin resistance in obese children and adolescents: HOMA-IR cut-off levels in the prepubertal and pubertal periods. J Clin Res Pediatr Endocrinol 2010;2:100-6.

34. Salazar MR, Carbajal HA, Espeche WG, Dulbecco CA, Aizpurúa M, Marillet AG, et al. Relationships among insulin resistance, obesity, diagnosis of the metabolic syndrome and cardio-metabolic risk. Diab Vasc Dis Res 2011;8:109-16.

35. de Onis M, Onyango AW, Borghi E, Siyam A, Nishida C, Siekmann J. Development of a WHO growth reference for school-aged children and adolescents. Bull World Health Organ 2007;85:660-7.

36. Wallace TM, Matthews DR. The assessment of insulin resistance in man. Diabet Med 2002;19:527-34.

37. Back Giuliano Ide C, Caramelli B, Pellanda L, Duncan $\mathrm{B}$, Mattos S, Fonseca FH. I guidelines of prevention of atherosclerosis in childhood and adolescence. Arq Bras Cardiol 2005;85 Suppl 6:4-36.

38. Juárez-López C, Klünder-Klünder M, Medina-Bravo P, Madrigal-Azcárate A, Mass-Díaz E, Flores-Huerta S. Insulin resistance and its association with the components of the metabolic syndrome among obese children and adolescents. BMC Public Health 2010;10:318.

39. Madeira IR, Bordallo MA, Carvalho CN, Gazolla FM, de Souza FM, de Matos HJ, et al. The role of metabolic syndrome components and adipokines in insulin resistance in prepubertal children. J Pediatr Endocrinol Metab 2011;24:289-95.

40. Tester J, Sharma S, Jasik CB, Mietus-Snyder M, Tinajero-Deck L. Gender differences in prediabetes and insulin resistance among 1356 obese children in Northern California. Diabetes Metab Syndr 2013;7: 161-5.

41. Angulo N, de Szarvas SB, Mathison Y, Hadad E, González D, Hernández A, et al. Diagnosis of insulin resistance by indirect methods in obese school children. Invest Clin 2013;54:149-60.

42. Kim HA, Lee SY, Kwon HS, Lee SH, Jung MH, Han K, 
et al. Gender differences in the association of insulin resistance with metabolic risk factors among Korean adolescents: Korea National Health and Nutrition Examination Survey 2008-2010. Diabetes Res Clin Pract 2013;99:54-62.

43. Romualdo MC, Nóbrega FJ, Escrivão MA. Insulin resistance in obese children and adolescents. J Pediatr
(Rio J) 2014;90:600-7.

44. Tandon N, Garg MK, Singh Y, Marwaha RK. Prevalence of metabolic syndrome among urban Indian adolescents and its relation with insulin resistance (HOMA-IR). J Pediatr Endocrinol Metab 2013;26: 1123-30. 